\title{
SPIRITUALITY, DEPRESSION, AND ANXIETY AMONG OCEAN SURFERS
}

A THESIS SUBMITTED TO THE GRADUATE DIVISION OF THE UNIVERSITY OF HAWAI'I AT MĀNOA IN PARTIAL FULFILLMENT OF THE REQUIREMENTS FOR THE DEGREE OF

\section{MASTER OF ARTS}

IN

\author{
PSYCHOLOGY
}

MAY 2013

By

Michael Amrhein

Thesis Committee:

Elaine Heiby, Chairperson

Harald Barkhoff

Kentaro Hayashi

Keywords: surfing, spirituality, depression, anxiety 


\begin{abstract}
Although research on the psychological correlates of ocean surfing is scarce, substantial anecdotal evidence suggests that the sport offers a uniquely positive experience for surfers. Prior research has demonstrated that surfers report fewer symptoms of depression and anxiety than the general population, but no explanation for these findings has been identified (Levin \& Taylor, 2011). Greater spirituality has been correlated with lower depression and anxiety, and many surfers have described surfing as a spiritual experience, indicating a potential connection between surfing and spirituality. The current study had several goals. The first goal was to partially replicate previous findings that surfers in California report less depressive and anxiety symptoms than the general population with a more geographically diverse sample of surfers (Levin \& Taylor, 2011). The second goal was to determine whether a geographically diverse group of surfers report a higher level of spirituality than the general population. The third goal of this study was to determine whether spirituality is related to depression and anxiety in this sample of surfers. The fourth goal was to determine whether the surfing experience is related to general spirituality. The fifth and final goal of this study was to determine whether the surfing experience is related to levels of depression and anxiety. One hundred surfers were recruited from the Hawaiian Islands and the Mid-Atlantic region of the East Coast. Participants were asked to complete a survey consisting of a consent form, a demographics questionnaire, the Spirituality Assessment Scale (SAS; Howden, 1992), the Beck Depression Inventory-II (BDI-II; Beck, Steer, \& Brown, 1996), and the Beck Anxiety Inventory (BAI; Beck \& Steer, 1993). The demographics questionnaire was used for descriptive purposes as well as an estimate for surfingspecific spiritual experiences. Scores on the SAS, BDI-II, and BAI were compared to available cutoff scores for each measure to provide a preliminary interpretation of the sample's scores.
\end{abstract}


Independent samples t-tests were also conducted to compare the scores on the SAS, BDI-II, and BAI with comparative normative groups. Correlational analyses on the scores of these measures were also computed to determine the relationship between reported levels of spirituality and the reported levels of depression and anxiety. Correlational analyses were also conducted to determine if any relationships existed between the surfing experience and spirituality, depression, and anxiety. Results of these analyses indicate that surfers from the Hawaiian Islands and the East Coast report fewer symptoms of depression and anxiety than most available comparative normative groups. Results also indicate that a relationship exists between reported greater levels of spirituality and reported lower levels of depressive symptomatology. Finally, the results show that a significant relationship exists between the surfing experience and reported levels of spirituality. The importance and limitations of these findings are discussed, as are implications for future research directions. 


\section{TABLE OF CONTENTS}

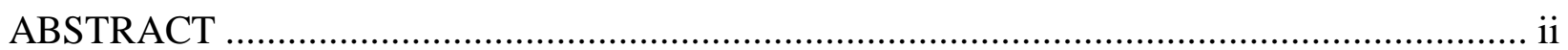

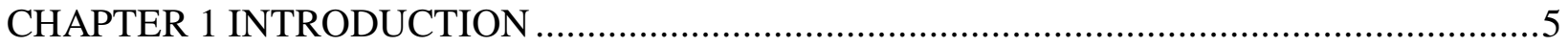

Surfing - Definition, Prevalence, and History ......................................................5

Psychological Correlates of Surfing ..................................................................... 7

Spirituality - Definition.............................................................................. 9

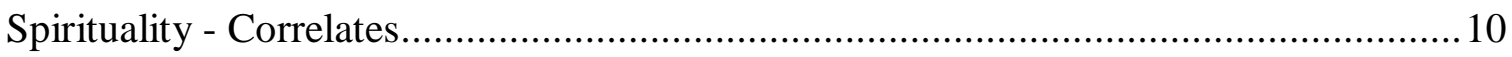

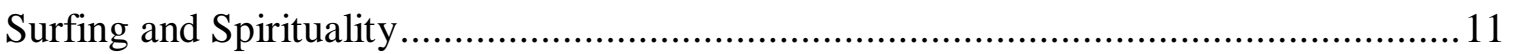

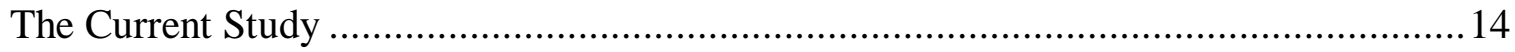

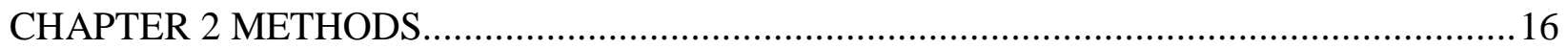

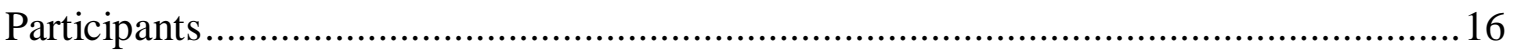

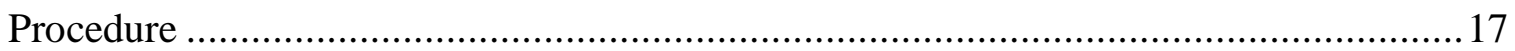

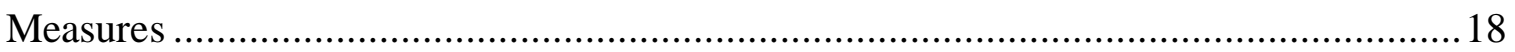

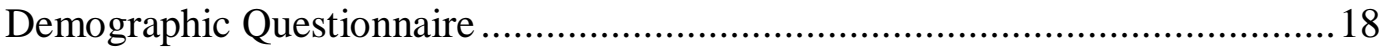

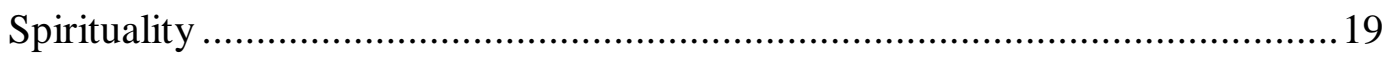

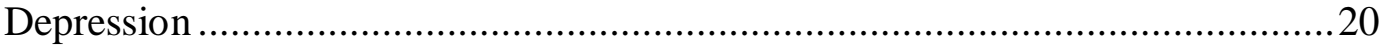

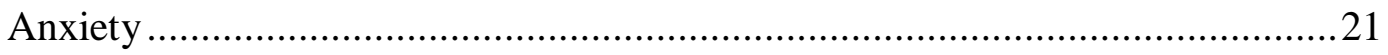

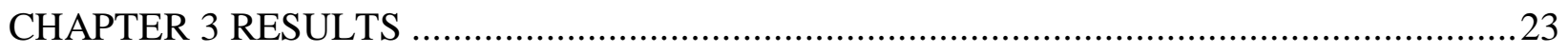

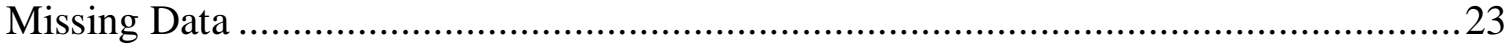

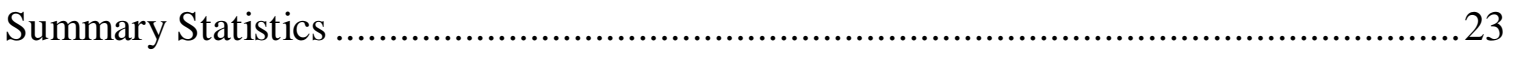

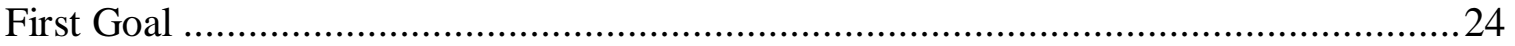

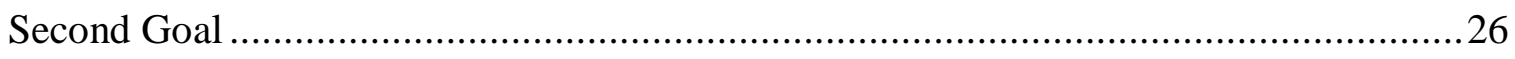

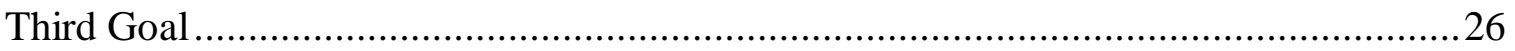

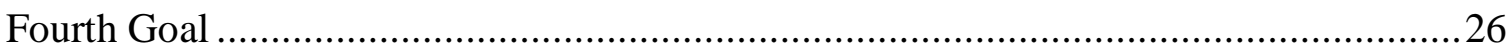

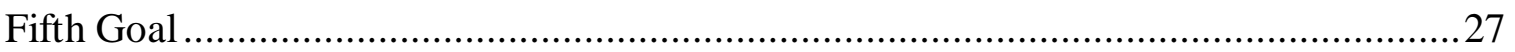

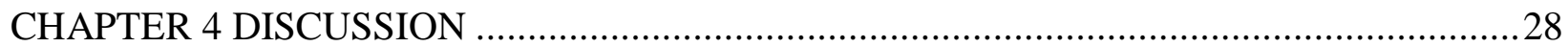

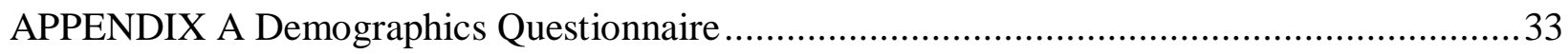

APPENDIX B Spirituality Assessment Scale .......................................................... 35

APPENDIX C Beck Depression Inventory II ........................................................ 38

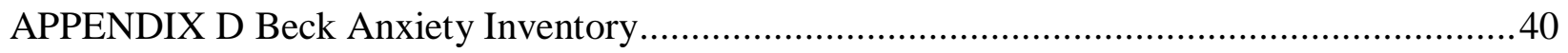

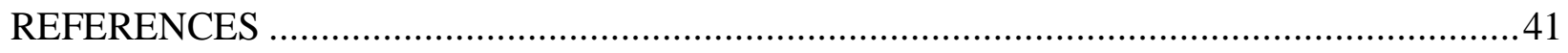




\section{CHAPTER 1}

\section{INTRODUCTION}

In recent years, there has been a growing interest in promoting an empirical evaluation of the positive mental health aspects of the spiritual nature of a variety of sport activities (Parry, Robinson, Watson, \& Nesti, 2007). The current study aims to explore the spiritual nature of ocean surfing and to address previous findings that surfers report fewer symptoms of depression and anxiety than the general population (Levin \& Taylor, 2011). This study seeks to partially replicate these findings in a geographically diverse sample of surfers. This study also aims to determine whether a geographically diverse group of surfers report higher levels of spirituality than the general population as well as explore spirituality's potential relationship with reported levels of depression and anxiety. The relationship between the surfing experience and reported levels of spirituality, depression, and anxiety are also explored. Surfing is defined and a brief history of the sport is discussed. Available psychological literature on the sport is reviewed. Similarly, a definition of spirituality is offered, and relevant correlates of spirituality are examined. Finally, substantial anecdotal evidence linking surfing and spirituality is discussed.

\section{Surfing - Definition, Prevalence, and History}

Surfing is an activity which involves standing on a surfboard while riding waves as they break. While there are many different forms of recreational wave riding, surfing will be defined in this study as the act of paddling on one's stomach on a surfboard as an ocean wave approaches and pushing one's self into a standing position as the wave begins to break and the momentum of the wave begins to propel the surfboard and surfer. Based on this definition, surfers who ride various surfboard models, such as longboards, shortboards, and fish models were included as potential participants in the study as all of these boards require the surfer to paddle for a wave and make the transition from lying on one's stomach to standing on one's feet. Conversely, other wave riding enthusiasts, such as boogie boarders, kneeboarders, skimboarders, kiteboarders, windsurfers, and stand-up paddleboarders, were excluded from the study.

The earliest known form of recreational wave riding is estimated to have begun around 1,000 B.C.E. off the coast of Huanchaco, Peru, although some scholars still debate that it may 
have originated even earlier. Fishermen from this area would ride the waves toward the shore in small, reed boats called caballitos (Warshaw, 2010). Surfing, as defined above, emerged as a recreational pastime in the Hawaiian Islands around the year 1,200 C.E., and it quickly became enmeshed in the Hawaiian culture. Surfing was practiced across all social classes and became intertwined with sex, politics, religion, and entertainment (Finney, 1959). It was an intricate part of the Makahiki harvest festival, which was celebrated in honor of the Hawaiian god Lono, a god of fertility, peace, and music (Finney, 1959). Rituals and prayers also played critical roles in the construction of a surfboard. A kumu fish would be placed as an offering at the trunk of a tree before it was cut down (Finney, 1959). The fish was then buried in a hole dug from the tree's root system as prayers were made. Additional rites and prayers would be performed before the surfboard was first launched into the water (Finney, 1959). Despite surfing's steady importance in the Hawaiian culture for hundreds of years, the arrival of American Calvinist missionaries in the early nineteenth century nearly eradicated the sport, which was seen to violate their own view of organized religion (Finney, 1960). The push for the adoption of Western religion and values by these early missionaries caused many Hawaiian traditions and customs to suffer, and surfing, which was generally practiced in the nude and had close ties to sexual activities, was no exception (Finney, 1960). The spiritual and sexual nature of surfing was seen as inconsistent with the dogma of Calvinism and was therefore repressed (Finney, 1960).

Despite these setbacks, surfing experienced a revival beginning at the turn of the twentieth century. Some Hawaiians continued to surf after the arrival of the Western missionaries, and the sport was slowly beginning to reemerge as a part of the Hawaiian culture (Finney, 1960). In the early part of the twentieth century, Olympic gold medalist swimmer Duke Kahanamoku became surfing's defining ambassador. By performing surfing exhibitions on beaches in Australia and the continental United States, Kahanamoku exposed surfing to new groups of people outside of the Hawaiian Islands (Finney, 1960). With Kahanamoku's exhibitions and a ringing endorsement for the sport by writer Jack London following a surfing experience while on a vacation in Waikiki, Hawai'i, surfing's popularity slowly began to grow (Warshaw, 2010). The 1930's and 1940's saw surfing slowly assimilate into the California culture, but still only a few thousand people around the world participated in the sport (Warshaw, 2010). However, during the late fifties and sixties, technological advancements in surfboard 
design and wetsuits made surfing more accessible and enjoyable for a larger population. Also around this time, iconic movies such as Gidget and The Endless Summer cemented surfing's place in the American culture, and spurred the transformation of the sport into the multi-billion dollar a year industry enjoyed by millions of people across the globe that is seen today (Warshaw, 2010). While the exact number is not known, estimates from the early 2000's of the total number of surfers worldwide ranged from five million to 23 million (Warshaw, 2005).

\section{Psychological Correlates of Surfing}

The psychological literature on surfing is scarce, but several studies have been conducted examining the motivations and mental health benefits of the sport. The literature review was completed through the use of the PsycINFO, EBSCOHost, and Google Scholar databases. Keywords used to conduct the search included surf, surfing, surfers, surfing psychology, and surfing sports psychology. Publications from all years were accepted. Published articles examining an aspect of psychology in surfers and/or surfing were included in the literature review.

Farmer (1992) investigated the motivations for surfing across six domains. The results of this study showed that 50 male surfers rated vertigo, which refers to the thrill or high accompanying an activity which may include the experience of self-transcendence or loss of self, as the highest motivating factor for surfing. Aesthetic and cathartic motivations consistently received high ratings, while social, health/fitness, and competition motivations were rated the lowest by this sample of surfers.

In terms of personality characteristics, surfers have been found to score higher on sensation seeking and openness to experience scales than athletes participating in the lower-risk sport of golf (Diehm \& Armatas, 2004). Surfers were also found to report higher levels of intrinsic motivation and similar levels of extrinsic motivation when compared to golfers (Diehm \& Armatas, 2004).

Surfers have described having experiences with and becoming dependent on flow states that occur during surfing (Partington, Partington, \& Olivier, 2009). Csikszentmihalyi (1975) describes flow as an optimal state of experience in which an individual feels a sense of complete 
control as well as a fusion between self and environment. Flow experiences provide individuals with a sense of growth and intrinsic enjoyment. During a flow state, the individual is said to be living completely in the moment and has a narrowed, intense focus on the activity at hand (Csikszentmihalyi, 1975). Partington et al. (2009) investigated the flow experiences of "big wave" surfers and found that they reported improved mood states, better surfing performance, and higher self-esteem and fulfillment as a result of these experiences. Surfers also reported an "addiction" to these feelings which led to their continued involvement in big wave surfing regardless of family commitments, potential injuries, or even potential death (Partington, et al., 2009).

Surfing has also been recently linked to mental health benefits. Levin \& Taylor (2011) found that a sample of 100 surfers in California reported significantly fewer symptoms of depression and anxiety than the general population. Research is also currently assessing the utility of surfing as a preventative approach to social and health problems in at-risk children (Morgan, 2010). Sunset Surfers is a program that teaches surfing to children in a disadvantaged, urban neighborhood in Australia. The children in this neighborhood are at high risk for child abuse and neglect. Preliminary qualitative evidence from the children, parents, and staff members suggest that the children demonstrated higher self-esteem and a new enthusiasm for overcoming and mastering challenges (Morgan, 2010). More research needs to identify other immediate benefits as well as the long-term effects of this surf program.

While the scientific research on surfing is limited, these studies indicate that surfers may experience an intrinsic reward which has led them to continue surfing. Many activities provide individuals with similar peak experiences and flow states, as well as mental health benefits. Art, music, games, and other sports are just a few examples (Csikszentmihalyi, 1975). However, a substantial amount of anecdotal evidence exists to suggest that surfers experience something unique, which cannot be fully described by peak or flow experiences. Surfers are willing to risk serious injury or death in order to reach the fulfillment surfing offers (Partington et al., 2009). In his article, "Is God a Goofyfoot?" (2005), published in Surfer Magazine, Brad Melekian, one of the magazine's journalists, claims that, 
"I could spend literal hours every day reading mail about people who claim surfing as a salvation. It's a phenomenon, really. And it's one, I believe, that is unique to surfing. I mean, do you think tennis players feel like they're getting any spiritual fulfillment out of their daily matches? Does the mail department at Gun World have a hard time handling the letters from readers about the spirituality of firing a .357? Probably not."

Melekian also remarks that the editors of the magazine could fill the editorial pages for years just with letters written by surfers describing their spiritual surfing quests and experiences. Numerous quotes from surfers have also paid homage to the impact surfing can have on an individual. John McCarthy stated simply, "Surfing is the most blissful experience you can have on this planet, a taste of heaven" (Wade, 2011). The anecdotal stories surrounding surfing point to the possibility that there is a spiritually powerful and unique experience to surfing that is found in few other activities. This spiritual aspect of surfing could offer an explanation for the previously found mental health benefits experienced by surfers.

\section{Spirituality - Definition}

Spirituality has been shown to be an important component of the human experience. It is an integral part of being human, and it can provide individuals with answers to common existential issues, such as purpose and sense of direction in one's life (D'Souza, 2007). In the Pew Forum's (2009) nationwide survey of 4,013 adults, $49 \%$ of the people reported experiencing a moment of religious or spiritual awakening, and $65 \%$ reported belief in or experience with at least one of the following supernatural phenomena: Belief in reincarnation, belief in spiritual (i.e., non-physical) energy located in physical things, belief in yoga as a spiritual practice, belief that certain people can cast curses or spells that cause bad things to happen to someone, belief in astrology, having been in touch with the dead, consulting a psychic, or encountering a ghost ("Many Americans," 2009). Baker (2003) argues for a number of benefits of spirituality including stronger identity development, higher perceived quality of life, more capable coping abilities, and a tool of empowerment to overcome obstacles. Baker also states that it can help people make sense of their lives by providing a framework in which to review and interpret life events and experiences. Spirituality can also provide people with a sense of meaning, peace, and connectedness (Tanyi, 2002). Spirituality acts as a vitalizing force in people's lives by making 
them feel more alive and energized (So, 2009). It has been shown to provide adolescents with a "path to purpose" at a time when many struggle to find their identity and place in the world (Tirri \& Quinn, 2010).

General consensus on the definition of spirituality has yet to be established, but Tanyi (2002) identified several defining characteristics of spirituality following an extensive review of the literature. These common themes from the literature include belief and faith, connectedness, inner peace, transcendence, and meaning and purpose in life. A distinction is also made between spirituality and religion, with religion referring to an organized institution that contains certain practices, traditions, rituals, and beliefs about a higher power (Tanyi, 2002). In this study, spirituality will be defined in terms of several components. First, there is a sense of connectedness within the individual with nature or the environment, all living beings, and a higher power. Second, there is a feeling of heightened self-awareness. Third, there is an awareness of a transcendent reality beyond the normal confines of time and space. Fourth, it provides the individual with feelings of inner peace and harmony and a sense of meaning and purpose in life. Fifth, it includes the belief that consciousness persists after physical death.

\section{Spirituality - Correlates}

Individuals in tune with their own spirituality demonstrate positive mental health outcomes in areas such as depression and anxiety. Increased spirituality has been shown to lead to better psychological well-being in adults who recently experienced a spousal loss (Fry, 2001). McClain et al. (2003) found that spirituality is also significantly correlated with less psychological distress in terminally-ill cancer patients. Patients who showed a stronger sense of spirituality displayed less hopelessness $(\mathrm{r}=-0.68, \mathrm{p}<0.0001)$, less suicidal ideation $(\mathrm{r}=-0.41$, $\mathrm{p}<0.0001)$, and less desire for hastened death $(\mathrm{r}=-0.51, \mathrm{p}<0.0001)$. Similarly, in a study seeking to identify the individual effects of spirituality and religion on depressive symptoms in terminally-ill patients, regression analysis demonstrated that spirituality was significantly associated with these symptoms $(\beta=-0.34, \mathrm{p}<0.001)$, while religiosity showed a negligible relationship $(\beta=0.09, \mathrm{p}=0.21)$ (Nelson et al., 2002). This result supports the notion that spirituality and religiosity are separate entities, and it also suggests that spirituality plays a role in certain domains of psychological well-being. Spirituality has also been significantly correlated 
with lower levels of depression $(\mathrm{r}=-0.862, \mathrm{p}<0.001)$ and anxiety $(\mathrm{r}=-0.0645, \mathrm{p}<0.001)$, and higher levels of quality of life in several domains including physical well-being $(\mathrm{r}=0.676$, $\mathrm{p}<0.001)$, social well-being $(\mathrm{r}=0.515, \mathrm{p}<0.001)$, emotional well-being $(\mathrm{r}=0.684, \mathrm{p}<0.001)$, and family well-being $(\mathrm{r}=0.655, \mathrm{p}<0.001)$ in patients with advanced cancer (Kandasamy et al., 2011).

Coward (1996) has found that spirituality is also linked to psychological characteristics for healthy populations. Coward found that self-transcendence, an aspect of spirituality, is significantly correlated with self-esteem $(r=0.51, p<0.01)$, hope $(r=0.66, p<0.01)$, purpose in life $(\mathrm{r}=0.76, \mathrm{p}<0.01)$, and sense of coherence $(0.58, \mathrm{p}<0.01)$. Tuck et al. (2006) found a negative significant correlation between stress and spirituality well-being in a population of 27 healthy adults following a spiritual intervention $(\mathrm{r}=-0.855, \mathrm{p}<0.01)$. The authors also discovered that a six week spiritual intervention led to a significant decline in levels of perceived stress $(F=4.21$, $\mathrm{p}<0.05)$ and a significant increase in spiritual perspective $(F=3.60, \mathrm{p}<0.05)$. In a study of 45 atrisk, yet healthy, adolescents, males with higher spiritual well-being showed significantly less state-trait anxiety $(r=-0.58, p<0.01)$, but this effect was not found in females ( $r=$ not reported) (Davis, Kerr, \& Kurpius, 2003). The authors suggested that the lack of an effect with females may be due to the higher overall anxiety in the female participants as compared to the male participants. The authors proposed that spirituality may only have an effect on trait anxiety within a moderate range of trait anxiety scores (Davis et al., 2003).

\section{Surfing and Spirituality}

Benjamin and Looby (1998) proposed a theory of spiritual development, which states that spiritual development occurs through one spiritual experience after another, with these repeated experiences ultimately leading to spiritual transformation. Spiritual transformation is finally achieved when an individual develops a new way of life, in both thought and spirit, through the individual's new awareness of his or her own spirituality (Benjamin \& Looby, 1998). Activities linked to spiritual transformation, such as meditation and yoga, fit the theory of spiritual development in that multiple spiritual experiences are required before a transformation can occur (Astin, 1997; Schure, Christopher, \& Christopher, 2008). Surfing may also fall into this category. If the anecdotal evidence for surfing as a spiritual experience is supported objectively, then 
surfers may display a high sense of spirituality because these repeated experiences would have resulted in a spiritual transformation.

Substantial anecdotal evidence exists connecting surfing with spirituality. For the ancient Hawaiians, surfing was intricately intertwined with religious practices and spirituality (Warshaw, 2010). Modern day surfers continue to manifest aspects of spirituality through their words and actions. One aspect of spirituality, a sense of connectedness, is evident in surfers across the globe. A major distinction between surfing and many other activities is a communion with nature. Surfers are able to experience the power, beauty, and harshness of nature in a unique way. Surfing in the warm, clear waters of the Hawaiian Islands can highlight the beauty of nature, while surfing during the frigid Northeast winters in the United States can remind many surfers of its extreme austerity. Surfers are also constantly at the ocean's mercy, as waves are affected by countless variables, such as tides, winds, and swell direction, and some storms can create mammoth, life-threatening waves. A certain knowledge and appreciation of the ocean is necessary to understand surfing, and as a result, many surfers feel a particular bond with the ocean, the ocean's inhabitants, and nature in general. Legendary surfer Duke Kahanamoku acknowledged his connection with the ocean by saying, "Out of water, I am nothing" (Wade, 2011). Because of this bond with nature, many surfers have become active defenders of the ocean and environment.

The Surfrider Foundation is an activist organization founded in 1984 to protect oceans and beaches around the world ("Mission," 2011). It is comprised primarily of surfers and has been instrumental in halting the destruction of several famous waves and the surrounding environments, including Malibu and Trestles, California. The foundation also leads campaigns to address other environmental concerns, such as recycling, reducing harmful runoff waste, and cleaning oceans and beaches following oil spills ("Mission," 2011). This organization is one of many which underline the connection surfers feel with the ocean and nature, as they demonstrate surfers' desire to preserve and conserve the environment.

Considerable evidence suggests that surfers also feel a connection with others and a higher power. Bonds can form quickly between surfers, and numerous surf clubs and organizations exist around the world allowing surfers to develop relationships with each other. 
Many surfers also become involved in movements to help people in need and spread feelings of peace in the world. The surfing company, Hurley, currently runs the $\mathrm{H} 2 \mathrm{O}$ Campaign which is a surfer led effort to provide clean water to people who currently do have not have access to it. The Malloy brothers, Chris, Keith, and Dan who are California natives of Irish descent, have used surfing as a medium to repair the relationship of the peoples of Northern Ireland and Southern Ireland. The Malloys set up a learn-to-surf program in which they brought kids from both factions of the island together with the common goal of learning to surf (Brown, 2003). The children were able to leave any prejudices aside and enjoy the sport together. Several adults watching the scene commented on how moving it was (Brown, 2003). The Malloy brothers hope that these types of efforts can eventually eliminate the division and prejudices between the groups, and that the people of Ireland can live in peace together.

The connection surfers feel to a higher power dates back to the ancient Hawaiians. The Hawaiians incorporated surfing into their religious festival celebrating the god Lono, and an assortment of prayers and rituals were performed throughout the board construction process (Finney, 1959). Modern day surfers continue to describe surfing and their subsequent experiences with nature as mediums through which they feel connected with a higher power. Surfing pioneer Tom Blake once carved, "Nature = God," on a rock in Wisconsin, where he lived out the second half of his life (Lynch, 2011). Andy Irons, a three-time Association of Surfing Professionals World Champion, said that surfing, "is the closest thing you can feel to being kissed by God" (Melekian, 2010). Taylor (2007) proposed that surfing has become a new religion with its own rites, rituals, and myths. Taylor argues that a certain group of surfers, the "soul surfers," consider surfing and the ocean as sacred with the potential to heal or transform. Levin and Taylor (2011) found that seventy-five percent of the surfers they sampled in California reported that riding a wave led to feelings of a connection with God, nature, or the universe. This piece of evidence highlights the multiple domains of connectedness experienced by surfers.

Heightened self-awareness, another component of spirituality, is part of the surfing experience. Riding a wave is commonly described by surfers as a meditative experience, as exemplified by Paul Walker's quote in which he states, "Surfing soothes me, it's always been a kind of Zen experience for me. The ocean is so magnificent, peaceful, and awesome. The rest of the world disappears for me when I'm on a wave" ("Surfer quotes," 2010). As mentioned above, 
Farmer (1992) found that vertigo, which may include feelings of self-transcendence or loss of self, was the main motivating factor for surfing. Partington et al. (2009) found that big wave surfers craved the flow states they experienced, which include a heightened sense of focus and self-awareness.

In addition, some surfers report experiences of a transcendent reality beyond the normal confines of linear time and three-dimensional space. Surfers have reported feeling that time slowed down significantly while surfing a wave. Steven Kotler (2007) describes such an experience in his book West of Jesus: Surfing, Science, and the Origins of Belief, where time seemed to pass so slowly that he could see every inch and nuance of the water, and he was able to perform a series of complex surfing maneuvers he had never before attempted. Kotler also speaks of an out-of-body experience while surfing in which he felt as though he was watching

himself ride the wave and enjoyed a 360 degree range of vision. This type of anecdotal evidence makes the potential connection between surfing and spirituality both plausible and compelling.

The final aspect of the proposed definition of spirituality which has been connected with surfing is feelings of inner peace, harmony, and meaning. Levin and Taylor (2011) have found that a sample of surfers in California report significantly fewer symptoms of depression and anxiety than the general population. Because surfers will frequently describe surfing as a meditative experience, they may reap the same psychological benefits of experienced meditators (e.g. Astin, 1997; Schure, et al., 2008). Levin and Taylor speculate the findings may be related to mindfulness, which is a very similar construct to spirituality. While a connection cannot be firmly established from this evidence alone, it is possible that the lack of inner turmoil experienced by surfers is due to a strong sense of spirituality, which includes feelings of peace, harmony, and meaning.

\section{The Current Study}

This study aimed to accomplish five goals. The first was to partially replicate the findings of Levin and Taylor (2011) that surfers report fewer symptoms of depression and anxiety than the general population. While the Levin and Taylor study investigated surfers in California, this partial replication includes a more geographically diverse sample of surfers who engage in their sport in either the Hawaiian Islands or the mid-Atlantic region of the East Coast of the United 
States. The second goal of this study was to determine whether a geographically diverse group of surfers reports higher levels of spirituality than the general population. While copious amounts of anecdotal evidence exist to suggest that such a relationship does exist, this goal has yet to be measured objectively. If a relationship is established, then these findings serve as a possible explanation for the mechanism behind previous scientific research on the mental health of surfers, particularly the connection between surfing and low symptoms of depression and anxiety. The third goal of this study was to determine whether the reported levels of spirituality from a geographically diverse sample of surfers are related to reported levels of depression and anxiety. The fourth goal was determine whether a relationship exists between the surfing experience and reported levels of general spirituality. The fifth and final goal of this study was to determine whether the surfing experience is related to reported levels of depression and anxiety. 


\section{CHAPTER 2}

\section{METHODS}

\section{Participants}

Surfers were sampled from both the Hawaiian Islands and the Mid-Atlantic region of the East Coast in the United States. The final sample included 100 participants, the same N-size used by Levin and Taylor (2011). Participants ranged from ages 18 to 62, with the mean age being 29.71 ( $\mathrm{SD}=10.69$ ) years old. The sample was $78 \%$ male and $22 \%$ female. In terms of ethnicity, $51 \%$ of the participants self-identified as being Caucasian, $20 \%$ as being mixed ethnicity, $10 \%$ as Japanese, 5\% as Hawaiian or part-Hawaiian, 3\% as Chinese, 3\% as Filipino, 2\% as Pacific Islander, $2 \%$ as Korean, $1 \%$ as African American, $1 \%$ as Hispanic, and 2\% as an ethnicity of "other."

Additionally, demographic information was obtained about the participants' surfing habits. Of the participants, $37 \%$ reported that they had been surfing for 12 or more years, $11 \%$ reported that they had been surfing for 9-11 years, 20\% reported surfing for 6-8 years, 19\% reported surfing for 3-5 years, and 13\% reported surfing for 0-2 years. Regarding frequency of surfing, $20 \%$ of participants reported that they surf, on average, 20 days or more each month, $11 \%$ reported surfing 15-19 days per month, 35\% reported surfing 10-14 days per month, $22 \%$ reported surfing 5-9 days per month, and 19\% reported surfing 0-4 days per month. Regarding duration of surf sessions, $28 \%$ of participants reported that their typical surf sessions, on average, last for 121 minutes or more, 30\% reported they surf for 91-120 minutes, 37\% reported that they surf for 61-90 minutes, 4\% reported that they surf for 31-60 minutes, and 1\% reported that they surf for 0-30 minutes. Regarding location of surfing, 26\% of participants reported that they most frequently surf on the East Coast of the United States, 3\% reported that they most frequently surf on the West Coast of the United States, 69\% reported that they surf most frequently in the Hawaiian Islands, and 2\% reported that they most frequently surf in a place other than those mentioned above. Regarding recency of the latest surf session, 59\% of the participants reported that the last time they had surfed was the same day they filled out the questionnaire, $25 \%$ reported it had been in the past week, $4 \%$ reported within the past two weeks, $3 \%$ reported within the past month, $8 \%$ reported within the past six months, and $1 \%$ reported it had been six months 
or longer. Finally, $76 \%$ of the participants reported that they engage in regular exercise beyond surfing, while $23 \%$ reported that they did not engage in any other exercise activities.

Recruiting methods were multi-faceted in both geographic regions. Following the example of Levin and Taylor (2011), surfers were recruited on the beach by the author approaching anyone with a surfboard and offering the opportunity to volunteer to participate in a study on surfing and mental health that involved completing a survey. On the island of Oahu in Hawai' $i$, this recruiting tactic took place on the beaches of Waikiki and the North Shore because of the high density of surfers in these areas. In the Mid-Atlantic region, surfers were approached along the beaches of Ocean City, Maryland because of its dense surfer population within several small stretches of beach and its accessibility for the author. A second recruiting technique used in this study was conducted in two large universities. Undergraduate surfers were recruited through their courses and surf clubs at the University of Hawai'i at Mānoa and the University of Maryland, College Park. Finally, employees were recruited in surf shops around Waikiki Beach, the North Shore of Oahu, and Ocean City, Maryland. All participants, regardless of where they were recruited, were offered surf wax, wax combs, or surf stickers in return for completing the survey.

\section{Procedure}

The study was approved by the University of Hawai'i at Mānoa Committee on Human Studies Institutional Review Board prior to data collection. Potential participants were asked to complete a brief survey, which was estimated to take approximately 15 to 20 minutes to finish. Participants then received the survey which included an informed consent form, a demographic questionnaire, the Spirituality Assessment Scale (Howden, 1992), the Beck Depression Inventory-II (Beck, Steer, \& Brown, 1996), and the Beck Anxiety Inventory (Beck \& Steer, 1993). The informed consent was always first in the survey, the demographic questionnaire was always second, and the order of the final three measures was counterbalanced. Consent forms were removed from completed surveys and given to the participants to keep, and each participant was assigned a number code to protect confidentiality. The author placed all completed surveys in an opaque envelope after completion. This envelope was then kept in a locked filing cabinet, and the author was the only person with a key to access the surveys. Participants received surf 
wax, wax combs, or surf stickers following the completion of the survey. Data entry was conducted primarily by the author and all computer data files were password protected.

\section{Measures}

Demographic Questionnaire. The demographic questionnaire (see Appendix A) was used to ask participants of their age, sex, and ethnicity. It also was used to ask the surfer to identify the number of years he or she has been surfing, how many days in a month he or she surfs on average, the average duration of his or her surf sessions in minutes, the geographic region he or she most frequently surfs, the amount of time since the individual has last surfed, and exercise habits aside from surfing.

Additionally on the Demographics Questionnaire, the surfer was asked to identify how frequently he or she experiences the sensation of 16 typical descriptors of surfing experiences, referred to as the Spiritual Surfing Experience Questionnaire (SSEQ). This list of items is based on the questionnaire generated by Levin \& Taylor (2011), with several modifications. The original item of feeling a connection with God, nature, or the universe was divided into three separate items, instead of clustering these choices together, several items (intense, dizzying, powerful, playful) were deleted because of a lack of relevance to the proposed definition of spirituality, and surfers were asked to rate these items on a five point Likert scale rather than an implicit dichotomous yes-no format. Responses to each item ranged from "Very Rarely," which received a score of one, to "Very Often," which received a score of five. These descriptors seem to provide surfing-specific indicators of spirituality as they address four of the five components of the proposed definition of spirituality. The components of spirituality which seem to be indicated from these items are connectedness (e.g. \#7), heightened self-awareness (e.g. \#4), a sense of a transcendent reality (e.g. \#5), feelings of inner peace and harmony, and a sense of meaning and purpose (e.g. \#3). Possible scores on this scale ranged from 16-80, with higher scores reflecting more endorsement of surfing-specific indicators of spirituality. The items "frightening" and "aggressive" were reversed scored. Using a Likert scale rating system allowed more sensitive correlations to be made between scores on the SSEQ and scores on the SAS, BDIII, and BAI. These correlations provided surfing-specific criterion validity estimates of the SAS, and the correlations with the BDI-II and BAI provided construct validity evidence of surfing- 
specific spiritual experiences. Reliability and validity estimates for the original and revised Levin and Taylor (2011) items are unknown.

Spirituality. The level of spirituality in participating surfers was assessed through the Spirituality Assessment Scale (SAS; Howden, 1992; Appendix B). The SAS is a self-report measure containing 28 items rated on a scale from one to six, where one is "Strongly Disagree" and six is "Strongly Agree." Possible scores on the SAS range from 28-168, with higher scores reflecting more endorsement of spirituality. Recommended cutoff scores were created to identify varying degrees of spirituality with 140-160 indicating strong, positive spirituality, 84-112 indicating fair or mixed positive and negative spirituality, and 28-56 would represent weak or negative spirituality (Howden, 1992). The mean test score in the initial normative sample of 189 predominantly white/Caucasian (94.7\%) adults between the ages of 40 and 60 living in the southwestern United States was 139.18 (SD=14.30) (Howden, 1992). The SAS was selected for this study because the items in the measure cover all five aspects of the proposed definition of spirituality used in this study. Items $1,2,4,6,7,9$, and 19 pertain to a sense of connectedness, items $8,10,13,14,23$, and 24 pertain to heightened self-awareness, items $3,10,11$, and 15 pertain to transcendence, items $5,12,16,17,18,20,21,22$, and 28 pertain to inner peace, harmony, meaning, and purpose, and item 11 pertains to the belief that consciousness persists after physical death. The SAS was also chosen because of its relatively short administration and strong psychometric support (Howden, 1992).

Reliability of the SAS has been assessed by measuring the internal consistency of the scale. The results of this analysis yielded a Chronbach's alpha correlation coefficient of 0.9164, indicating that the items are inter-related (Howden, 1992). No other forms of reliability were established. Therefore, the stability of scores over time is unknown. Construct validity was established through factor loading. The results of this analysis produced six factors with a factor loading criteria of 0.40 and a minimal loading of three items on a single factor (Howden, 1992). The six factors produced were innerness expressed as harmony and relationship with a supreme being, innerness utilized for guidance and strength, connectedness to others, connectedness to life and the world, meaning and purpose in life, and transcendence (Howden, 1992). These six factors correspond to the proposed definition of spirituality in this study, and the items in the measure capture each of the components of the definition as indicated above. Criterion validity 
was demonstrated through correlations with two measures of behaviors deemed to be weakly positively related or unrelated to spirituality. Scores on the SAS showed a significant, yet weak, positive relationship with religiousness, as measured by a single item designed by Howden (1992) which asked participants to rate themselves on a scale in terms of their overall level of religiousness from "Not at all" to "Very religious" ( $\mathrm{r}=0.2447)$, and religiousness accounted for approximately six percent of the variance in SAS scores $\left(r^{2}=0.0598\right)$ (Howden, 1992). Scores on the SAS were not significantly correlated with frequency of attendance at religious events, as measured by a single item designed by Howden (1992) which asked participants to rate their frequency of attending religious events on a scale from "At least once a week" to "Not at all" $(\mathrm{r}=0.0598)$, and frequency of attendance at religious events accounted for $0.36 \%\left(\mathrm{r}^{2}=0.0036\right)$ of the variance in SAS scores (Howden, 1992). These convergent and divergent validity estimates indicate that the SAS is measuring spirituality in a way that is largely independent of religious beliefs or practices.

Depression. The Beck Depression Inventory-II was used to measure the level of depressive symptoms among participating surfers (BDI-II; Beck, Steer, \& Brown, 1996; Appendix C). The BDI-II is a self-report instrument containing 21 items rated on a scale from zero to three, with a minimum score of zero and a maximum score of 63 . Higher scores reflect more endorsement of depressive symptoms. Recommended cutoff scores were created to identify varying degrees of depression, with 0-13 indicating minimal depression, 14-19 indicating mild depression, 20-28 indicating moderate depression, and 29-63 indicating severe depression (Beck et al., 1996). A predominantly white/Caucasian sample of 120 college students with a mean age of 19.58 ( $\mathrm{SD}=$ unknown) years was administered the test to serve as a comparative normal group (Beck et al., 1996). This sample yielded a mean test score of 12.56 (SD=9.93) (Beck et al., 1996). In a separate normative study, the non-depressed group in a sample of 127 adults seeking therapy from the University of Pennsylvania yielded a mean score on the BDI-II of 7.65 $(\mathrm{SD}=5.90)$ (Beck et al., 1996). The BDI-II was selected for this study because of its relatively short administration time and strong psychometric support (Beck et al., 1996).

Reliability of the BDI-II has been established through internal consistency and test-retest analyses. Internal consistency analysis of the scores from a sample of 500 outpatients yielded a Chronbach's alpha correlation coefficient of 0.92 (Beck et al., 1996). Analysis of the scores from 
a sample of 120 college students yielded a Chronbach's alpha correlation coefficient of 0.93 (Beck et al., 1996). These estimates indicate that the items are highly inter-related. Test-retest reliability in a sample of 26 outpatients over a one week interval had a correlation of 0.93 (Beck et al., 1996), suggesting the scores are stable across seven days. Construct validity was documented through factor analysis of the scores from a sample of 500 outpatients. The analysis yielded the two factors of somatic-affective and cognitive symptoms (Beck et al., 1996). Criterion and construct validity were established with several other scales. The BDI-II was significantly correlated with the Scale for Suicide Ideation ( $r=0.37$; Beck, Kovacs, \& Weissman, 1979) and the Hamilton Psychiatric Rating Scale for Depression (r=0.71; Hamilton, 1960), indicating that the BDI-II is similar to other measures of depression and depressive symptoms (Beck et al., 1996). The BDI-II was also significantly correlated with the Hamilton Rating Scale for Anxiety ( $r=0.47$; Hamilton, 1959) and the Beck Hopelessness Scale ( $r=0.68$; Beck \& Steer, 1988), indicating that the BDI-II is related to theoretically similar measures (Beck et al., 1996). A study with 127 students yielded a $93 \%$ true positive rate and an $18 \%$ false positive rate (Beck et al., 1996).

Anxiety. The level of anxiety symptoms among participating surfers was assessed through the Beck Anxiety Inventory (BAI; Beck \& Steer, 1993; Appendix D). The BAI is a self-report instrument containing 21 items rated on a scale from zero to three with a minimum score of zero and a maximum score of 63 . Higher scores reflect more endorsement of anxiety symptoms. Recommended cutoff scores were created to identify varying degrees of anxiety, with 0-7 indicating minimal anxiety, 8-15 indicating mild anxiety, 16-25 indicating moderate anxiety, and 26-63 indicating severe anxiety (Beck \& Steer, 1993).Three non-clinical samples were administered the BAI to serve as normative comparison groups. Among the normative comparison groups, 65 college students had a mean test score of 11.08 (SD=9.1), 142 medical students had a mean test score of 8.89 (SD=7.30), and 36 non-student adults had a mean score of $7.78(\mathrm{SD}=5.65)$ The BAI was selected for this study because of its relatively short administration time and strong psychometric support (Beck \& Steer, 1993).

Reliability of the BAI has been established through internal consistency and test-retest analyses. Internal consistency analysis of scores on the BAI in adult samples yielded Chronbach's alpha correlation coefficients ranging from 0.92 to 0.94 , indicating high inter- 
relatedness of the items (Beck \& Steer, 1993). Test-retest reliability during a one week interval was 0.75 , indicating stability of scores over a seven day period (Beck \& Steer, 1993). Criterion validity was established through correlations with two scales designed to measure anxiety. The BAI was significantly correlated with the Hamilton Anxiety Rating Scale ( $r=0.51$; Hamilton, 1959), the mean anxiety ratings over a seven day period in the Weekly Record of Anxiety and Depression ( $\mathrm{r}=.54$; Barlow \& Cerny, 1988), and both the Trait (r=0.47) and State ( $\mathrm{r}=0.58)$ subscales of the State-Trait Anxiety Inventory (Spielberger, Gorsuch, \& Lushene, 1970; Beck \& Steer, 1993). 


\section{CHAPTER 3}

\section{RESULTS}

\section{Missing Data}

Missing data comprised $0.41 \%$ of all possible responses in the entire questionnaire packet. No individual item on any of the questionnaires was missing more than $3 \%$ of possible responses. To determine if data were missing systematically or at random, Little's Missing Completely at Random test was conducted (Little, 1988). Results of the test indicated that the null hypothesis should be accepted, which suggests that the data were missing completely at random (Chi-Square=1195.49; p-value=0.394). Therefore, single imputation procedures can be justified and were used to fill the missing data.

\section{Summary Statistics}

The internal consistency reliabilities of the SSEQ, SAS, BDI-II and BAI were estimated using coefficient alphas. For the SSEQ, Cronbach's Alpha was 0.72. For the SAS, Cronbach's alpha was 0.924. For the BDI-II, Cronbach's Alpha was 0.821. Finally, for the BAI, Cronbach's Alpha was 0.9. Prior to any additional analyses, demographic variables and total mean scores were compared between the sample of surfers from Hawai' $i(n=69)$ and the surfers from the East Coast ( $n=26)$. Using a z-test to compare the proportions, there were no significant differences between the proportions of males $(\mathrm{z}=0.47$; $\mathrm{p}$-value $=0.67)$ within the two groups $(77 \%$ of surfers from Hawaii were male; $81 \%$ of surfers from East Coast were male). An independent samples ttest revealed that there were differences between the groups based on age $(t=2.81 ; p$-value $<0.01)$, with participants who reported surfing most frequently in the Hawaiian Islands being significantly older $(\mathrm{M}=31.57 ; \mathrm{SD}=10.5)$ than those who reported surfing most frequently on the East Coast of the United States ( $M=24.85 ; \mathrm{SD}=10.1)$. Additionally, based on eye-balling the data, there were differences between the groups based on ethnicity. In the group of surfers from the East Coast, $96 \%$ identified as Caucasian and $4 \%$ identified a mixed ethnicity. In the group of surfers from the Hawaiian Islands, 33\% identified as Caucasian, 1\% as African American, 3\% as Chinese, $4 \%$ as Filipino, 7\% as Hawaiian or Part-Hawaiian, 14\% as Japanese, 3\% as Korean, 3\% as Pacific Islander, $1 \%$ as Hispanic, $3 \%$ as an ethnicity of "other," and $28 \%$ as a mixed ethnicity. 
Additionally, independent samples t-tests were conducted on the mean scores on SSEQ, SAS, BDI-II, and BAI. There were no significant score differences found between surfers from the Hawaiian Islands and surfers from the East Coast on the SSEQ ( $\mathrm{t}=1.26$; $\mathrm{p}$-value=0.21), the SAS $(t=1.28 ; p$-value $=0.21)$, the BDI-II $(t=0.5$; $\mathrm{p}$-value $=0.62)$, or the BAI $(t=0.45 ; \mathrm{p}$ value $=0.65$ ). Additionally, a one-way Analyses of Variance (ANOVA) was conducted to determine if there were any differences between participants based on which geographic region they reported surfing within most frequently, as some participants indicated that they surf most frequently on the West Coast $(n=3)$ of the United States or within "other" geographic regions $(\mathrm{n}=2)$. There were no significant differences found between geographic groups on the SSEQ $(\mathrm{F}=0.63$; $\mathrm{p}$-value=0.596), the SAS $(\mathrm{F}=0.63 ; \mathrm{p}$-value=0.595), the BDI-II $(\mathrm{F}=0.96$; $\mathrm{p}$-value=0.417), or the BAI ( $\mathrm{F}=0.17$; $\mathrm{p}$-value=0.92). Despite differences between the groups in age and ethnicity, no significant differences were found on the SSEQ, SAS, BDI-II, or BAI. Therefore, these groups were combined for all subsequent statistical analyses.

\section{First Goal}

The first goal of this study was to partially replicate the findings of Levin and Taylor (2011) that surfers report fewer symptoms of depression and anxiety than the general population. To address this goal, comparisons between obtained scores and normative scores were performed on the BDI-II and BAI in two ways.

The first method was comparing the scores from the sample of surfers to the recommended cutoff scores available for each scale by computing the total mean scores of each scale and identifying within which range these means fall. For the BDI-II, the total score mean of the sample was 4.43, which falls within the cutoff range of minimal depressive symptomatology (Beck et al., 1996). The total score mean of the sample on the BAI was 5.61, which falls within the cutoff range of minimal anxiety symptomatology (Beck \& Steer, 1993). These findings are consistent with those of Levin and Taylor (2011), suggesting geographically diverse surfers have a euthymic mood and are relaxed.

The second method was comparing the sample's mean scores on the BDI-II and BAI with normative sample means through independent samples t-tests. The total mean score for the sample of surfers on the BDI-II $(M=4.43 ; \mathrm{SD}=4.34 ; \mathrm{n}=100)$ was compared both to the mean 
score in the normative sample of 120 college students $(M=12.56 ; \mathrm{SD}=9.93)$ and the mean score in a separate normative sample of the non-depressed group of 127 adults $(\mathrm{M}=7.65 ; \mathrm{SD}=5.90)$ seeking therapy (Beck et al., 1996). The total mean score from the sample of surfers was significantly lower than the total mean score of the normative sample of 120 college students $(t=-$ 8.09; $\mathrm{p}$-value $<0.01$ ) and the total mean score of the normative sample of 127 non-depressed adults seeking therapy $(\mathrm{t}=-4.73$; $\mathrm{p}$-value $<0.01)$. Total scores on the BDI-II were also used to compare the percentage of participants who endorsed clinically significant levels of depressive symptoms with the point prevalence in the United States $(8.7 \%)$ as reported from a survey of 217,379 individuals by Strine et al. (2008). In this sample, $4 \%$ of participants endorsed scores of 14 or above on the BDI-II, which indicates a clinically significant level of depression. Using a ztest to compare the proportions, the sample of surfers were found to have a significantly lower proportion of participants $(\mathrm{z}=2.39$; $\mathrm{p}$-value $<0.05)$ who endorsed a clinically significant level of depression than the point prevalence as reported by Strine et al. (2008). Therefore, this second method of assessing depression among surfers also suggests they are more likely to experience a euthymic mood than the population at large.

The total mean score on the BAI $(M=5.63 ; \mathrm{SD}=6.87 ; \mathrm{n}=100)$ was compared to the total mean score in a normative sample of 65 college students $(\mathrm{M}=11.08, \mathrm{SD}=9.1)$, the total mean score in a normative sample of 142 medical students $(M=8.89, \mathrm{SD}=7.30)$, and the total mean score in a normative sample of 36 non-students $(\mathrm{M}=7.78, \mathrm{SD}=5.65)$ (Beck \& Steer, 1993). The total mean score of the sample of surfers was significantly lower than the total mean score of the normative sample of 65 college students $(\mathrm{t}=-4.14$; $\mathrm{p}$-value $<0.01)$ and the total mean score of the normative sample of 142 medical students $(\mathrm{t}=-3.56$; $\mathrm{p}$-value $<0.01)$. However, the total mean score on the BAI from the sample of surfers was not significantly different than the normative sample of 36 non-students ( $\mathrm{t}=-1.86$; $\mathrm{p}$-value=0.06). These findings are largely consistent with those of Levin and Taylor (2011), who found that surfers reported lower levels of depression and anxiety than these normative samples. These results indicate that the sample of surfers in this study mostly also reported fewer symptoms of depression and anxiety than the available normative samples for the BDI-II (Beck et al., 1996) and BAI (Beck \& Steer, 1993). 


\section{Second Goal}

The second goal of this study was to determine whether a geographically diverse group of surfers reported higher levels of spirituality than the general population. In addressing this goal, the total mean score from the sample of surfers on the SAS was compared to the recommended cutoff scores available for this scale to identify within which range this mean score falls. On the SAS, the total score mean of the sample was 137.27, which falls between the cutoff ranges of fair or mixed positive and negative spirituality (range=84-112) and strong, positive spirituality (range=140-160) (Howden, 1992). Additionally, the total mean score of the sample on the SAS $(\mathrm{M}=137.27 ; \mathrm{SD}=16.13 ; \mathrm{n}=100)$ was compared to the mean score in the normative sample of 189 adults $(\mathrm{M}=139.18, \mathrm{SD}=14.30)$ through the use of an independent samples t-test (Howden, 1992). The total mean score of the sample of surfers was not significantly different than the normative sample of 189 adults $(\mathrm{t}=-0.995 ; \mathrm{p}$-value $=0.32)$. These results indicate that the sample of surfers did not report a higher overall level of spirituality than the available normative sample for the SAS (Howden, 1992).

\section{Third Goal}

The third goal of this study was to determine whether the reported levels of spirituality from a geographically diverse sample of surfers are related to reported levels of depression and anxiety. In regards to this goal, the overall level of spirituality's relationship with reported levels of depression and anxiety was examined. Correlational analyses were conducted using scores on the SAS, BDI-II, and BAI to ascertain which relationships, if any, exist between these variables. The analyses yielded a significant, negative correlation between scores on the SAS and scores on the BDI-II ( $\mathrm{r}=-0.312$; $\mathrm{p}$-value<0.01). No significant correlation was found between scores on the SAS and scores on the BAI ( $\mathrm{r}=-0.118$; $\mathrm{p}$-value=0.242). Therefore, a greater degree of spirituality was related to a lower degree of depression but not to anxiety, providing mixed support for the third goal of this study.

\section{Fourth Goal}

The fourth goal of this study was to determine whether a relationship exists between the surfing experience and reported levels of general spirituality. To address this goal, the 
relationship between the surfing experience and overall levels of spirituality was examined. Correlational analysis was conducted to determine if a relationship existed between the scores on the SSEQ and the scores on the SAS. A significant, positive relationship was found between scores on the SSEQ and SAS ( $r=0.551$; $\mathrm{p}$-value $<0.01)$. These results indicate that a relationship does exist between the spiritual aspects of the surfing experience and reported levels of general spirituality.

\section{Fifth Goal}

The fifth and final goal of this study was to determine whether the spiritual aspects of the surfing experience were related to reported levels of depression and anxiety. Correlational analyses were conducted to determine if a relationship existed between the scores on the SSEQ and the scores on the BDI-II and BAI. A significant relationship was not found between scores on the SSEQ and BDI-II ( $\mathrm{r}=-0.002$; $\mathrm{p}$-value=0.987) or scores on the SSEQ and the BAI ( $\mathrm{r}=-$ $0.068 ; \mathrm{p}$-value $=0.504)$. These results indicate that the surfing experience did not have a relationship with either reported levels of depression or anxiety. 


\section{CHAPTER 4}

\section{DISCUSSION}

The results of this study support three of the original five goals of this study. First, regarding Goal One, the findings of Levin and Taylor (2011) that surfers in California reported a lower level of depression and anxiety than the general population were mostly replicated in this sample of surfers from the Hawaiian Islands and the East Coast of the United States. The total mean of reported levels of depressive symptomatology in this sample fell within the range for minimal depression and was significantly lower than the reported levels of two normative comparison groups (Beck et al, 1996). Additionally, the proportion of individuals within the sample who reported clinically significant levels of depression was significantly lower than the point prevalence rate as reported by Strine et al. (2008). Similarly, the total mean of reported levels of anxiety symptomatology in this sample fell within the range for minimal anxiety and was significantly lower than the reported levels of two (65 college students and 142 medical students) out of three normative comparison groups (Beck \& Steer, 1993). The total mean of the sample in this study was not significantly different than a sample of 36 non-students in terms of reported levels of anxiety (Beck \& Steer, 1993). This inconsistent result could be due to the small sample size in the third comparison group. These findings hold important implications for potential mental health promoting aspects of surfing which deserve further study.

Secondly, Goal Three was partially supported in this study insofar as a relationship was found between spirituality and depression. A significant, negative correlation was found between mean scores on the SAS and the BDI-II, indicating that participants who reported a higher level of overall spirituality also reported a lower level of depressive symptomatology. However, no significant relationship was found between mean scores on the SAS and BAI, indicating a lack of association between spirituality and anxiety. This result is inconsistent with previous findings (Kandasamy et al., 2011; Davis et al., 2003) and warrants future study.

Finally, support was found for Goal Four that the surfing experience is related to overall levels of spirituality. A significant, positive correlation was found between mean scores on the SSEQ and SAS, indicating that participants who reported a higher level of surfing-specific spiritual experiences also reported a higher level of overall spirituality. 
Two of the original five goals of this study were not supported. Goal Two of the study was not supported in that this sample of surfers did not report a significantly higher overall level of spiritualty than the available normative sample for the SAS (Howden, 1992). However, given the finding that the surfing experience was significantly related to overall levels of spirituality, there appears to be an association between reporting a high level of spiritual-specific surfing experiences and overall levels of spirituality. Future research should seek to identify the differences between surfers who report higher levels of spiritual-specific surfing experiences and those who do not. For example, frequency and duration of surfing sessions may affect degree of spirituality. Additionally, Goal Five of the study, which examined the relationship between the surfing experience and levels of depression and anxiety, was not supported. These results seem to indicate that there is no association between spiritual-specific surfing experiences and depressive or anxious symptomatology. Again, it is possible that frequency and duration of surfing sessions serve as moderating factors.

The results of this study hold important implications for investigating the causal mechanism behind the previous finding that surfers report fewer symptoms of depression and anxiety than the general population (Levin \& Taylor, 2011). These prior findings that the reported levels of depressive and anxiety symptoms are partially replicated in this study involving a more geographically diverse sample of surfers, which strengthens the hypothesis that surfing may be an experience which leads to these mental health benefits. As the sample in this study includes surfers from different geographic regions than the sample in the study by Levin and Taylor (2011), these findings demonstrate that surfers from a wide range of geographic regions share these common mental health characteristics. However, the results should still be generalized with caution, as these samples all come from regions within the United States, and may not be fully representative of the worldwide surfing population in terms of culture, age, ethnicity, or gender. Additionally, higher levels of spirituality were associated with lower levels of depression, which may indicate that spirituality could be a possible causal mechanism for the findings that surfers reported a lower level of depressive symptomatology than normative comparison samples in both of these studies. This potential mechanism could be based upon the definition of spirituality including factors such as a sense of connectedness and feelings of inner 
peace and harmony. Possession of these characteristics may result in lower depressive symptomatology.

In addition to partially replicating the findings of lower reported levels of depression and anxiety, a relationship was found between the surfing experience and overall levels of spirituality. These findings indicate that surfers who report a high level of surfing-specific spiritual experiences also report a high level of spirituality. This relationship supports anecdotal accounts which describe surfing as a spiritual experience for some individuals. However, this study does not address the issue of whether surfing-specific spiritual experiences lead to a higher sense of spirituality or whether highly spiritual people consider surfing to be a spiritual experience. It is possible that individuals who already possess a greater sense of spirituality interpret the experience of surfing in a spiritual manner. Future research should address this issue and also seek to determine the differences between individuals who report a higher level of surfing-specific spiritual experiences and those who do not.

Although the goal that surfers would report a higher overall level of spirituality than the general population was not supported (Goal Two), spirituality's relationship with the surfingexperience and levels of depressive symptomatology support the notion that spirituality is a relevant variable for this population. Future research is warranted to determine if other factors are contributing to the positive mental health qualities reported by surfers, such as the benefits of exercise or engaging in physical leisure activities. However, spirituality should also be considered in future research, particularly in terms of establishing causal relationships between the surfing experience and overall levels of spirituality (Parry et al., 2007).

There are several limitations to this study which need to be addressed. First, normative comparison samples were used which did not match the sample in this study in terms of culture, age, ethnicity, gender, or geographic location. The lack of a control group, such as a sample of non-surfers or other athletes who do not also surf, which was better matched to this sample on these characteristics hinders the generalizability of the results. Additionally, the psychometric properties of the SSEQ are unknown other than the Cronbach's Alpha of 0.72 and the significant concurrent criterion validity correlation between the SAS and SSEQ found in the present study. Without knowledge of other reliability and validity estimates of the scale, results should be 
interpreted with caution. A third limitation is that convenience sampling was used in that the geographic regions which were studied were of the easiest accessibility for the author. Also, there may be differences between individuals who agreed to participate in the study and those who did not, as some potential participants chose not to complete the survey when asked. While the refusal rate was not systematically noted, it is the impression of the researcher that approximately $20 \%$ of the surfers who were invited refused to participate. Finally, causal relationships are not able to be established from these results, as the relationships between variables are based on correlational rather than longitudinal analyses.

Surfing continues to grow as a sport of interest within the spirituality of sports literature, although, until now, this work has been exclusively theoretical and anecdotal (Parry et al., 2007). Due to this increasing interest, research should continue to focus on the spiritual aspect of surfing, as well as the mental health implications of the sport. Future research should seek to replicate these results with surfers in other geographic regions of the world, particularly in areas outside of the United States. These replications could lend further support to the notion that the unique experience of surfing may hold a causal mechanism behind the mental health benefits seen in this sample of surfers and in previous studies (Levin \& Taylor, 2011). Furthermore, future research should seek to determine causation between the correlations found in this study. Studies should address the relationships between the surfing experience and overall levels of spirituality, to see which variable precedes the other. Similarly, research should focus on the findings of the negative correlation between overall levels of spirituality and symptoms of depression, to determine if this is a causal relationship. Finally, future studies should strive to determine the differences between individuals who report a high level of surfing-specific spiritual experiences and those who do not, as well as the differences between surfers who report a high level of spirituality and those who do not. 


\section{APPENDIX A}

\section{Demographics}

Directions: Please answer the following questions in regards to your demographics. All responses will be kept confidential. Please mark the appropriate response or fill in the blank for each question.

1. What is your sex (check one)? a) Male

b) Female

c) Other

2. What is your age (in years)?

3. What is the ethnic background with which you most identify?
a. African American
b. Caucasian
c. Chinese
d. Filipino
e. Hawaiian or Part Hawaiian
f. Japanese
g. Korean
h. Pacific Islander
i. Portuguese
j. Asian other than listed above (please specify)
k. Hispanic (please specify)
1. Other (please specify)
m. Mixed (please specify)

4. How many years have you been surfing (check one)?
a) $0-2$
b) $3-5$
c) 6-8
d) $9-11$
e) 12 or more

5. On average, how many days in a month do you surf?
a) $0-4$
b) $5-9$
c) $10-14$
d) $15-19$
e) 20 or more

6. On average, how long does your typical surf session last, in minutes?
a) $0-30$
b) $31-60$
c) $61-90$
d) $91-120$
e) 121 or more

7. Where do you surf most frequently?
a. East Coast, USA
b. West Coast, USA
c. Hawaiian Islands
d. Other (Please specify)

8. When was the last time you surfed?
a) Today
b) Within the past week
c) Within the past two weeks
d) Within the past month
e) Within the past six months

f) More than six months ago

9. Do you do any regular exercise besides surfing? a) Yes

b) No

a. If yes, please specify what kind of exercise

b. On average, how many days in a month do you do this exercise?

c. On average, how many minutes do you do this exercise? 


\section{SSEQ}

Directions: Please indicate your response by circling the answer which best describes how frequently you experience each sensation while riding a wave, with "Very Rarely" being the least frequent and "Very Often" being the most frequent. All of your answers will remain confidential.

1. Fun

2. Frightening*

3. Blissful

4. Heightened focus

5. Time slowing down

6. Time speeding up

7. Connection with nature

8. Connection with God

9. Connection with the universe

10. Meditative

11. Aggressive*

12. Smooth

13. Stimulating

14. Less concerned with the outside world

15. Flow

16. Rush

*Denotes items to be reversed scored.
Very Rarely Rarely Sometimes Often Very Often

Very Rarely Rarely Sometimes Often Very Often

Very Rarely Rarely Sometimes Often Very Often

Very Rarely Rarely Sometimes Often Very Often

Very Rarely Rarely Sometimes Often Very Often

Very Rarely Rarely Sometimes Often Very Often

Very Rarely Rarely Sometimes Often Very Often

Very Rarely Rarely Sometimes Often Very Often

Very Rarely Rarely Sometimes Often Very Often

Very Rarely Rarely Sometimes Often Very Often

Very Rarely Rarely Sometimes Often Very Often

Very Rarely Rarely Sometimes Often Very Often

Very Rarely Rarely Sometimes Often Very Often

Very Rarely Rarely Sometimes Often Very Often

Very Rarely Rarely Sometimes Often Very Often

Very Rarely Rarely Sometimes Often Very Often 


\section{APPENDIX B}

\section{Spirituality Assessment Scale}

DIRECTIONS: Please indicate your response by circling the appropriate number indicating how you respond to each statement.

\section{Mark:}

$$
\begin{aligned}
& \text { " } 1 \text { " if you Strongly Disagree } \\
& \text { " } 2 \text { " if you Disagree } \\
& \text { " } 3 \text { " if you Disagree more than Agree } \\
& \text { " } 4 \text { " if you Agree more than Disagree } \\
& \text { " } 5 \text { " if you Agree } \\
& \text { "6" if you Strongly Agree }
\end{aligned}
$$

\begin{tabular}{|c|c|c|c|}
\hline & $\begin{array}{l}\text { Disagree } \\
\text { more than }\end{array}$ & $\begin{array}{l}\text { Agree } \\
\text { more than }\end{array}$ & \\
\hline isagree & Disagree Agree & Disagree & Agree \\
\hline
\end{tabular}

There is no "right" or "wrong" answer. Please respond to what you think or how you feel at this point in time.

1. I have a general sense of belonging. $\quad \begin{array}{llllllll}1 & 2 & 3 & 4 & 5 & 6\end{array}$

2. I am able to forgive people who have done me wrong.

$\begin{array}{llllll}1 & 2 & 3 & 4 & 5 & 6\end{array}$

3. I have the ability to rise above or go beyond a physical or psychological

$\begin{array}{llllll}1 & 2 & 3 & 4 & 5 & 6\end{array}$
condition.

4. I am concerned about the destruction of the environment.

$\begin{array}{llllll}1 & 2 & 3 & 4 & 5 & 6\end{array}$

5. I have experienced moments of peace in a devastating event.

6. I feel a kinship to other people.

$\begin{array}{llllll}1 & 2 & 3 & 4 & 5 & 6\end{array}$

7. I feel a connection to all life.

$\begin{array}{llllll}1 & 2 & 3 & 4 & 5 & 6\end{array}$

8. I rely on an inner strength in hard

$\begin{array}{llllll}1 & 2 & 3 & 4 & 5 & 6\end{array}$
times. 


\begin{tabular}{|c|c|c|c|}
\hline & $\begin{array}{l}\text { Disagree } \\
\text { more than }\end{array}$ & $\begin{array}{l}\text { Agree } \\
\text { more than }\end{array}$ & \\
\hline Disagree & Disagree Agree & Disagree & Agree \\
\hline
\end{tabular}

9. I enjoy being of service to others.

10. I can go to a spiritual dimension within myself for guidance.

11. I have the ability to rise above or go beyond a body change or body loss.

12. I have a sense of harmony or inner peace.

13. I have the ability for self-healing.

14. I have an inner strength.

15. The boundaries of my universe extend beyond usual ideas of what space and time are thought to be.

16. I feel good about myself.

17. I have a sense of balance in my life.

18. There is fulfillment in my life.

19. I feel a responsibility to preserve the planet.

20. The meaning I have found for my life provides a sense of peace.

$\begin{array}{llllll}1 & 2 & 3 & 4 & 5 & 6\end{array}$

$\begin{array}{llllll}1 & 2 & 3 & 4 & 5 & 6\end{array}$

$\begin{array}{llllll}1 & 2 & 3 & 4 & 5 & 6\end{array}$

$\begin{array}{llllll}1 & 2 & 3 & 4 & 5 & 6\end{array}$

21. Even when I feel discouraged, I trust that life is good.

$\begin{array}{llllll}1 & 2 & 3 & 4 & 5 & 6\end{array}$

22. My life has meaning and purpose.

23. My innerness or an inner resource $\begin{array}{llllll}1 & 2 & 3 & 4 & 5 & 6\end{array}$ helps me deal with uncertainty in life.

$\begin{array}{llllll}1 & 2 & 3 & 4 & 5 & 6\end{array}$




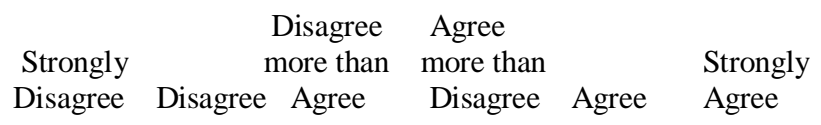

24. I have discovered my own strength in times of struggle.

25. Reconciling relationships is important to me.

$\begin{array}{llllll}1 & 2 & 3 & 4 & 5 & 6\end{array}$

26. I feel a part of the community in which I live.

$\begin{array}{llllll}1 & 2 & 3 & 4 & 5 & 6\end{array}$

27. My inner strength is related to a belief in a Higher Power or Supreme Being.

$\begin{array}{llllll}1 & 2 & 3 & 4 & 5 & 6\end{array}$

28. I have goals and aims for my life.

$\begin{array}{llllll}1 & 2 & 3 & 4 & 5 & 6\end{array}$




\section{APPENDIX C}

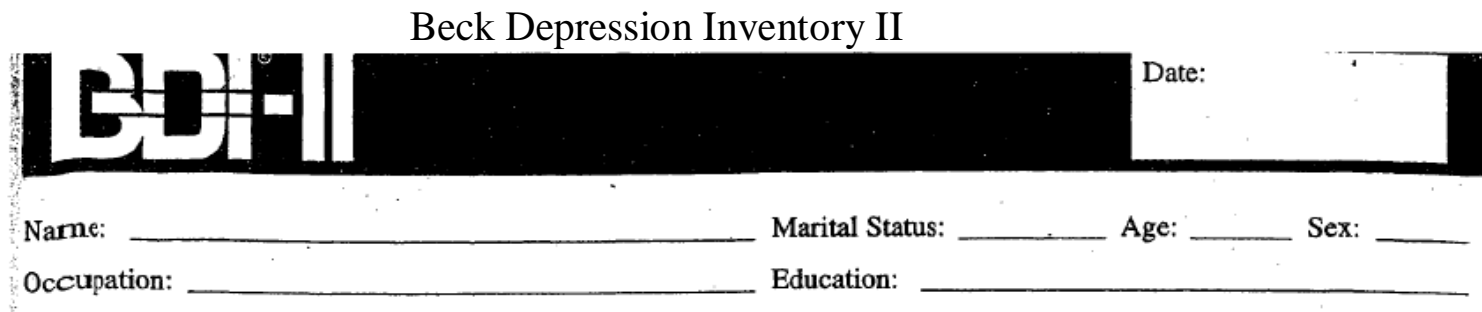

Instructions: This questionnaire consists of 21 groups of statements. Please read each group of statements carefully, and then pick out the one statement in each group that best describes the way you have been feeling during the past two weeks, including today. Circle the number beside the statement you have picked. If several statements in the group seem to apply equally well, circle the highest number for that group. Be sure that you do not choose more than one statement for any group, including Item 16 (Changes in Sleeping Pattern) or Item 18 (Changes in Appetite).

$$
\begin{aligned}
& \text { 1. Sadness } \\
& 0 \text { I do not feel sad. } \\
& 1 \text { I feel sad much of the time. } \\
& 2 \text { I am sad all the time. } \\
& 3 \text { I am so sad or unhappy that I can't stand it. }
\end{aligned}
$$

\section{Pessimism}

0 I am not discouraged about my future.

1 I feel more discouraged about my future than I used to be.

2 I do not expect things to work out for me.

3. I feel my future is hopeless and will only get worse.

\section{Past Failure}

0 I do not feel like a failure.

1 I have failed more than I should have.

2 As I look back, I see a lot of failures.

3 I feel I am a total failure as a person.

\section{Loss of Pleasure}

0 I get as much pleasure as I ever did from the things I enjoy.

1 I don't enjoy things as much as I used to.

2 I get very little pleasure from the things I used to enjoy.

3 I can't get any pleasure from the things I used to enjoy.

\section{Guilty Feelings}

0 I don't feel particularly guilty.

1 I feel guilty over many things I have done or should have done.

2 I feel quite guilty most of the time.

3 I feel guilty all of the time.

\section{Punishment Feelings}

0 I don't feel I am being punished.

1 I feel I may be punished.

2 I expect to be punished.

3 I feel I am being punished.

\section{Self-Dislike}

0 I feel the same about myself as ever.

1 I have lost confidence in myself.

2 I am disappointed in myself.

3 I dislike myself.

\section{Self-Criticalness}

0 I don't criticize or blame myself more than usual.

1 I am more critical of myself than I used to be.

2 I criticize myself for all of my faults.

3 I blame myself for everything bad that happens.

\section{Suicidal Thoughts or Wishes}

0 I don't have any thoughts of killing myself.

1 I have thoughts of killing myself, but I would not carry them out.

2 I would like to kill myself.

3 I would kill myself if I had the chance.

\section{Crying}

0 I don't cry anymore than I used to.

1 I cry more than I used to.

2 I cry over every little thing.

3 I feel like crying, but I can't

\section{(4) THE PSYCHOLOGICAL CORPORATION} Hancourt Brace \& Company 


\section{Agitation}

0 I am no more restless or wound up than usual.

1 I feel more restless or wound up than usual.

2 I am so restless or agitated that it's hard to stay still.

3 I am so restless or agitated that I have to keep moving or doing something.

\section{Loss of Interest}

0 I have not lost interest in other people or activities.

1 I am less interested in other people or things than before.

2 I have lost most of my interest in other people or things.

3 It's hard to get interested in anything.

\section{Indecisiveness}

0 I make decisions about as well as ever.

1 I find it more difficult to make decisions than usual.

2 I have much greater difficulty in making decisions than I used to.

3 I have trouble making any decisions.

\section{Worthlessness}

$0 \quad$ I do not feel I am worthless.

1 I don't consider myself as worthwhile and useful as I used to.

2 I feel more worthless as compared to other people.

3 I feel utterly worthless.

\section{Loss of Energy}

0 I have as much energy as ever.

1 I have less energy than I used to have.

2 I don't have enough energy to do very much.

3 I don't have enough energy to do anything.

\section{Changes in Sleeping Pattern}

0 I have not experienced any change in my sleeping pattern.

1a I sleep somewhat more than usual.

1b I sleep somewhat less than usual.

2a I sleep a lot more than usual.

$2 \mathrm{~b}$ I sleep a lot less than usual.

3a I sleep most of the day.

3b I wake up 1-2 hours early and can't get back to sleep.

\section{Irritability}

0. I am no more irritable than usual.

1 I am more irritable than usual.

2 I am much more irritable than usual.

3 I am irritable all the time.

\section{Changes in Appetite}

0 I have not experienced any change in my appetite.

1a My appetite is somewhat less than usual

1b My appetite is somewhat greater than usual.

2a My appetite is much less than before.

2b My appetite is much greater than usual.

3a I have no appetite at all.

$3 \mathrm{~b}$ I crave food all the time.

\section{Concentration Difficulty}

0 I can concentrate as well as ever.

1 I can't concentrate as well as usual.

2 It's hard to keep my mind on anything for very long.

3 I find I can't concentrate on anything.

\section{Tiredness or Fatigue}

0 I am no more tired or fatigued than usual.

1 I get more tired or fatigued more easily than usual.

2 I am too tired or fatigued to do a lot of the thing I used to do.

3 I am too tired or fatigued to do most of the things I used to do.

\section{Loss of Interest in Sex}

0 I have not noticed any recent change in my interest in sex.

1 I am less interested in sex than I used to be.

2. I am much less interested in sex now.

3 I have lost interest in sex completely.

NOTICE: This form is printed with both blue and black ink. If your copy does not appear this way, it has been photocopied in violation of copyright laws. 


\title{
APPENDIX D
}

\author{
Beck Anxiety Inventory
}

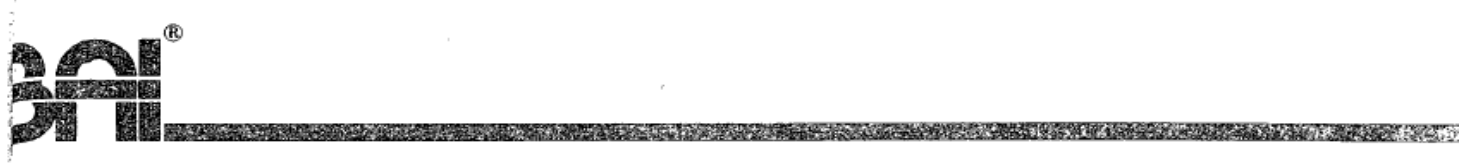

ME

DATE

ow is a list of common symptoms of anxiety. Please carefully read each item in the list. Indicate how much you have been bothered by each ptom during the PAST WEEK, INCLUDING TODAY, by placing an $X$ in the corresponding space in the column next to each symptom.

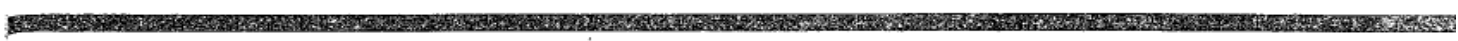

1. Numbness or tingling.

2. Feeling hot.

3. Wobbliness in legs.
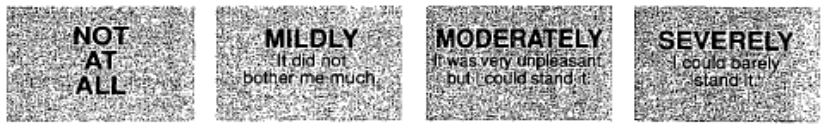

4. Unable to relax.

5. Fear of the worst happening.

6. Dizzy or lightheaded.

7. Heart pounding or racing.

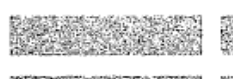

8. Unsteady.

9. Terrified.

10. Nervous.

11. Feelings of choking.

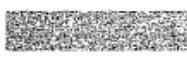
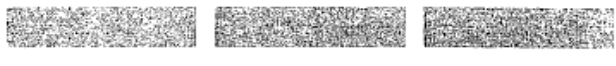

War

Wit
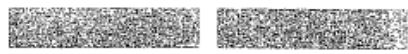

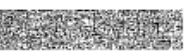

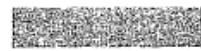

W.

(1)

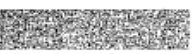

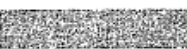

Fin

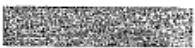

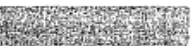

Mry

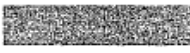

Wriver
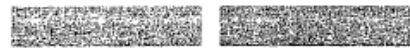

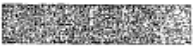

7.

vint

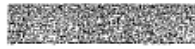

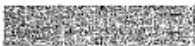

H.

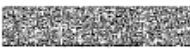

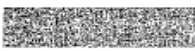
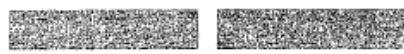

Fin.
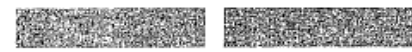

Fivis

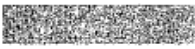

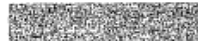

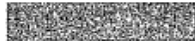

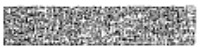

H.

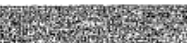

型

12. Hands trembling.

13. Shaky.

14. Fear of losing control.
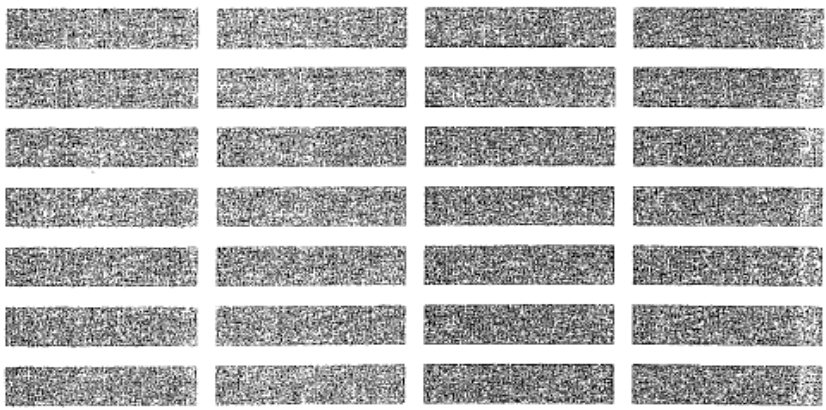

15 . Difficulty breathing.

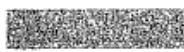

rFin:
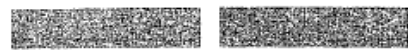

15y

16. Fear of dying.

17. Scared.

18. Indigestion or discomfort in abdomen.

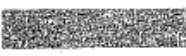

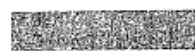
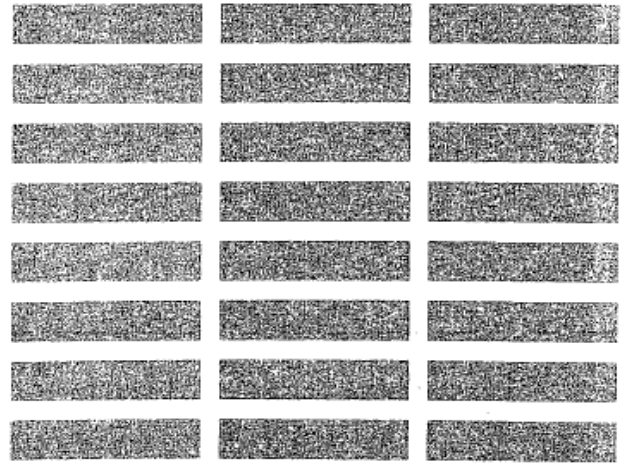

Frow
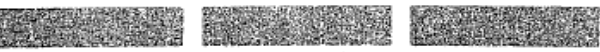

2.

19. Faint.
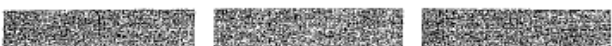

19xis

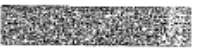

20. Face flushed.

21. Sweating (not due to heat).

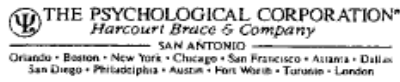
pyright 1990,1987 by Aaron T. Beck. All rights reserved. No part of this publication may be reproduced or transmitted in any form or by any means, electronic or mechanical.
fluding photocopy, recording. or any information storage and retrieval system, without permission in writing from the publisher. BAl is a registered trademark of The Psychological unding photocopy, recording, or any intormation Drintert in the I Initarl States of America.

Reproduced with permission of the copyright owner. Further reproduction prohibited without permission. 


\section{REFERENCES}

Astin, A. (1997). Stress reduction through mindfulness meditation. Psychotherapy and Psychosomatics, 66, 97-106.

Baker, D. (2003). Studies of the inner life: The impact of spirituality on quality of life. Quality of Life Research, 12, 51-57.

Barlow, D. H., \& Cerny, J. A. (1988). Psychological treatment of panic. Guilford Press.

Beck, A., Kovacs, M., \& Weissman, A. (1979). Assessment of suicidal intention: the Scale for Suicide Ideation. Journal of consulting and clinical psychology, 47(2), 343.

Beck, A, \& Steer, R. (1988). Beck hopelessness scale. San Antonio, TX: The Psychological Corporation.

Beck, A., \& Steer, R. (1993). Beck Anxiety Inventory manual. San Antonio, TX: The Psychological Corporation.

Beck, A., \& Steer, R., \& Brown, G. (1996). Beck depression inventory (2 ${ }^{\text {nd }}$ ed.: Manual). San Antonio, TX: The Psychological Corporation.

Benjamin P., \& Looby J. (1998) Defining the nature of spirituality in the context of Maslow's and Roger's theories. Counseling and Values, 49, 92-100.

Brown, D. (Director) (2003). Step into liquid [DVD].

Coward, D. (1996). Self-transcendence and correlates in a healthy population. Nursing Research, 45(2), 116-121.

Csikszentmihalyi, M. (1975). Beyond boredom and anxiety. San Francisco, CA: JosseyBass.

Davis, T., Kerr, B., \& Kurpius, S. (2003). Meaning, purpose, and religiosity in at-risk youth: The relationship between anxiety and spirituality. Journal of Psychology and Theology, 31(4), 356-365.

Diehm, R., \& Armatas, C. (2004). Surfing: An avenue for socially acceptable risk-taking, satisfying needs for sensation seeking and experience seeking. Personality and Individual Differences, 36, 663-677.

D’Souza, R. (2007). The importance of spirituality in medicine and its application to clinical practice. Medical Journal of Australia, 186(10), 57-59. 
Farmer, R. (1992). Surfing: Motivations, values, and culture .Journal of Sport Behavior, 15(3), 241-258.

Finney, B. (1959). Surfing in ancient Hawai'i. The Journal of the Polynesian Society, 68(4), 327-347.

Finney, B. (1960). The development and diffusion of modern Hawaiian surfing. The Journal of the Polynesian Society, 69(4), 314-331.Fry, P.S. (2001). The unique contribution of key existential factors to the prediction of psychological wellbeing of older adults following spousal loss. The Gerontologist, 41(1), 69-81.

Hamilton, M. (1959). The assessment of anxiety states by rating. British journal of medical psychology, 32(1), 50-55.

Hamilton, M. (1960). A rating scale for depression.Journal of Neurology and Neurosurgical Psychiatry, 23, 56-62.

Howden, J.W. (1992). Development and psychometric characteristics of the spirituality assessment scale (Doctoral Dissertation, Texas Woman's University, 1992). Dissertation Abstracts International, 54 (1-B), 166B.

Kandasamy A. \& Chaturvedi S. K., Desai G. (2011). Spirituality, distress, depression, anxiety, and quality of life in patients with advanced cancer. Indian Journal of Cancer, 48(1), 55-59.

Kotler, S. (2007). West of Jesus: Surfing, science, and the origins of belief. New York, NY: Bloomsbury USA.

Levin, B., \& Taylor, J. (2011). Depression, anxiety, and coping in surfers. Clinical Sport Psychology, 5, 148-165.

Little, R. (1988). A test of missing completely at random for multivariate data with missing values. Journal of the American Statistical Association, 83(404), 11981202.

Lynch, G. (2011). Tom Blake. Retrieved from http://surfmuseum.org/Tom\%20Blake.htm Many Americans mix multiple faiths: Eastern, new age beliefs widespread. (2009, December 09). Retrieved from http://www.pewforum.org/other-beliefs-andpractices/many-americans-mix-multiple-faiths.aspx

McClain, C., Rosenfeld, B., \& Breitbart, W. (2003). Effect of spiritual well-being on endof-life despair in terminally-ill cancer patients. The Lancet, 361, 1603-1607. 
Melekian, B. (2005). "Is God a Goofyfoot?", Surfer, 46/3, p. 115.

Melekian, B. (2010). Last drop. Retrieved from

http://www.outsideonline.com/outdoor-adventure/athletes/Last-rop.html?page=all

Mission. (2011). Retrieved from http://www.surfrider.org/pages/mission

Morgan, P. (2010). "Get up. Stand up." riding to resilience on a surfboard. Child and Family Social Work, 15, 56-65.

Nelson, C., Rosenfeld, B., Breitbart, W., \& Galietta, M. (2002). Spirituality, religion, and depression in the terminally ill. Psychosomatics, 43(3), 213-220.

Parry, J., Robinson, S., Watson, N., \& Nesti, M. (2007). Sport and spirituality: An introduction. New York, NY: Routledge.

Partington, S., Partington, E., \& Olivier, S. (2009). The dark side of flow: A qualitative study of dependence in big wave surfing. The Sport Psychologist, 23, 170-185.

Schure, M., Christopher, J., \& Christopher, S. (2008). Mind-body medicine and the art of self-care: Teaching mindfulness to counseling students through yoga, meditation, and Qigong. Journal of Counseling and Development, 86(1), 47-56.

So, T. Y. (2009). Pentecostal spirituality as nurturing vitality for human lives. Journal of Pentecostal Theology, 18, 246-262.

Spielberger, C. D., Gorsuch, R. L., \& Lushene, R. E. (1970). The state-trait anxiety inventory. Palo Alto, Calif: Consulting Psychologists Press Inc.

Strine, T., Mokdad, A., Balluz, L., Gonzalez, O., Crider, R., Berry, J., et al. (2008). Depression and anxiety in the United States: Findings from the 2006 behavioral risk factor surveillance system. Psychiatric Services (Washington, D.C.), 59, 1383-1390.

Surfer quotes. (2010). Retrieved from http://www.surfer-ways.com/surfer-quotes.html.

Tanyi, R. (2002). Towards clarification of the meaning of spirituality. Journal of Advanced Nursing, 39(5), 500-509.

Taylor, B. (2007). Surfing into spirituality and a new, aquatic nature religion. Journal of the American Academy of Religion, 75(4), 923-951.

Tirri, K., \& Quinn, B. (2010). Exploring the role of religion and spirituality in the development of purpose: Case studies of purposeful youth. British Journal of Religious Education, 32(3), 201-214. 
Tuck, I., Alleyne, R., \& Thinganjana, W. (2006). Spirituality and stress management in healthy adults. Journal of Holistic Nursing, 24(4), 245-253.

Wade, A. (2011). The top ten surfing quotes. Retrieved from http://www.swellwomen.com/swell-life/the-top-10-surfing-quotes

Warshaw, M. (2005). The encyclopedia of surfing. Boston, MA: Mariner Books.

Warshaw, M. (2010). The history of surfing. San Francisco, CA: Chronicle Books LLC. 